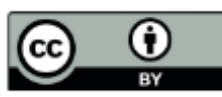

\title{
Processo de regionalização na Bahia, Brasil: \\ desafios para inovação organizacional*
}

\section{Proceso de regionalización en Bahia, Brasil: \\ desafíos para la innovación organizacional}

\section{Regionalization Process in Bahia, Brazil: Challenges for the Organizational Innovation}

Recepção: 20 de julho de 2018. Aprovação: 04 de junho de 2019. Publicação: 30 de junho de 2020.

DOI: https://doi.org/10.11144/Javeriana.rgps19.prbb

\author{
Adriano Maia dos Santos ${ }^{a}$ \\ Universidade Federal da Bahia, Brasil \\ ORCID: https://orcid.org/https://orcid.org/0000-0001-9718-1562 \\ Fabiana Rodrigues Ferreira dos Santos \\ Universidade Federal da Bahia, Brasil \\ ORCID: https://orcid.org/https://orcid.org/0000-0001-9091-0646 \\ Jamille Amorim Carvalho Paiva \\ Universidade Federal da Bahia, Brasil \\ ORCID: https://orcid.org/ https://orcid.org/0000-0003-2309-4559
}

\begin{abstract}
Como citar este artigo: Santos AM, Santos FRF, Paiva JAC. Processo de regionalização na Bahia, Brasil: desafios para inovação organizacional. Revista Gerencia y Políticas de Salud. 2020;19. https://doi.org/10.11144/ Jave riana.rgps 19.prbb
\end{abstract}

a Autor correspondente. Correio eletrônico: maiaufba@ufba.br 


\section{Resumo}

Introdução: As Diretorias Regionais de Saúde (Dires) tinham a função de desconcentrar as responsabilidades administrativas da Secretaria Estadual de Saúde da Bahia, além da incumbência de apoio à gestão da saúde junto aos municípios nas regiões de saúde. Em 2014, com a reforma administrativa na Bahia, as Dires foram extintas e criados os Núcleos Regionais de Saúde (NRS). Método: Trata-se de pesquisa qualitativa que analisou as mudanças ocorridas no processo de regionalização posterior à mudança das Dires em NRS. Resultados: tratou-se de decisão mais burocrática que técnica, abrupta e sem participação dos trabalhadores. A mudança trouxe grande sobrecarga a equipe de profissionais do NRS, o que prejudicou o andamento das atividades e projetos antes desenvolvidos pelas Dires. Conclusão: Permaneceram as antigas estruturas, mas com outros nomes. Houve aprofundamento das precárias estruturas de trabalho e o comprometimento da capacidade das "novas" instâncias em desenvolverem ações na direção do fortalecimento da regionalização, contradizendo a lógica de organização do Sistema Único de Saúde.

Palavras-chave: regionalização, planejamento em saúde, sistema único de saúde, integração de sistemas, sistemas de saúde.

\section{Resumen}

Introducción: Las Direcciones Regionales de Salud (Dires) tenían la función de desconcentrar las responsabilidades administrativas de la Secretaría Estadual de Salud de Bahia, además de la designación de apoyar la gestión de salud junto a los municipios en las regiones de salud. En 2014, con la reforma administrativa en Bahia, las Dires fueron acabadas y se crearon los Núcleos Regionales de Salud (NRS). Método: Se trató de una investigación cualitativa que analizó los cambios que se dieron en el proceso de regionalización posterior a la transformación de las Dires en NRS. Resultados: se encontró que se trató de una decisión más burocrática que técnica, abrupta y sin participación de los trabajadores. El cambio trajo una pesada sobrecarga al equipo de profesionales de los NRS, lo que perjudicó el avance de las actividades y proyectos antes desarrollados por las Dires. Conclusión: las antiguas estructuras permanecieron, pero con otros nombres. Hubo profundización de las precarias estructuras de trabajo y se comprometió la capacidad de las "nuevas" instancias en el desarrollo de acciones en dirección al fortalecimiento de la regionalización, contradiciendo la lógica de organización del Sistema Único de Salud.

Palabras clave: regionalización, planeamiento en salud, sistema único de salud, integración de sistemas, sistemas de salud.

\section{Abstract}

Introduction: Regional Health Directions (Dires, Portuguese acronym) were aimed to decentralize the administrative functions/responsibilities of the State Health Secretary in Bahia. In addition, they were commissioned to support health management together with the municipalities in the health regions. In 2014, after the administrative reform in Bahia, the Dires were shut down and the Regional Health Nuclei (NRS, Portuguese acronym) were created. Method: It is a qualitative research to study the changes due to the regionalization process after transforming the Dires into NRS. Results: This study found that it was a bureaucratic decision rather than a technical one; it was abrupt and without any participation by the workers. The changes brought about a heavy work overload to the professionals in the NRS and all this was detrimental to the activities and projects being developed by the Dires. Conclusion: The old structures remained but their names were changed. There was an escalation in the structural precariousness and the capacity of the "new" divisions for developing actions intended to strengthen the territorialization was compromised. This fact goes against the organizational logic of the Sole Health System.

Keywords: regionalization, health planning, sole health system, systems integration, health systems. 


\section{Introdução}

A regionalização da rede de serviços de saúde é um princípio estruturante do Sistema Único de Saúde (SUS), que retornou à agenda política brasileira no início dos anos $2000 \mathrm{com}$ a Norma Operacional da Assistência à Saúde (1), com o Pacto pela Saúde (2) e, mais recentemente, com o Decreto 7.508 (3).

Nada obstante, o processo de regionalização tem assumido diferentes significados (4, 5), adotando diferentes caminhos e distintos ritmos, conforme os contextos e seus condicionantes institucionais e políticos nas unidades federadas diante da necessidade de gestão compartilhada entre diferentes entes para provimento dos serviços de saúde à população $(6,7,8)$.

No Brasil, a regionalização caracteriza-se pela busca de integração de sistemas de serviços de saúde municipais, em redes de atenção à saúde de âmbitos regional e macrorregional, com importantes desafios em relação à garantia do acesso e à estrutura de governança do sistema (9). Tal modelagem aumenta a complexidade na gestão de redes para produção do cuidado integral (10), porquanto deve conciliar interesses conflitantes de diferentes municípios, respeitando a sua autonomia política, financeira e administrativa, ao mesmo tempo em que deve buscar a construção de um modelo solidário e cooperativo no financiamento e na prestação dos serviços de saúde $(11,12)$. Por conseguinte, "envolvem jogos de cooperação e competição, acordos, vetos e decisões conjuntas entre governos que possuem interesses e projetos frequentemente divergentes na disputa política" (13).

O arcabouço do federalismo brasileiro, que se estrutura mediante três entes autônomos de governo (União, estados e municípios), torna, ainda mais, complexa a implantação e gestão de políticas sociais, como o SUS, e as estratégias de organização regional, uma vez que "procede da necessidade basilar de integrar seus componentes para garantir a efetivação do direito à saúde" (14). Neste contexto, a esfera estadual assume importância fulcral na configuração do arranjo federativo e na condução das políticas públicas em outros países (15), muito embora, no Brasil, permaneça sendo um tema controverso.

Por este prisma, para articular a integração dos serviços fracionados entres os municípios, a formação de redes compartilhadas pode garantir a qualificação da gestão do SUS e assegurar a integralidade do cuidado em contextos marcados pela heterogeneidade territorial e socioeconômica $(16,17)$. Portanto, a implementação da regionalização tenta suplantar as barreiras de acesso geradas com a municipalização $(6,18)$, o que requer a participação da esfera estadual, com o objetivo de assegurar a integralidade aos serviços de saúde e harmonizar princípios de autonomia e interdependência político-administrativa dos municípios $(15,19)$.

Segundo Teixeira et al. (20), até final dos anos oitenta, não existia uma política de regionalização territorial-populacional na Secretaria Estadual de Saúde da Bahia (Sesab), embora reconheçam alguns elementos normativos que apontavam para essa direção e que advinham da experiência dos anos 1960-70 com a Reforma Administrativa do Estado e criação dos Centros Executivos 
Regionais de Saúde (CERS). Destacam, ainda, que a criação das Diretorias Regionais de Saúde (Dires), na década de 1980, no âmbito da Sesab, e o protagonismo da Bahia, ao ser o primeiro estado a assinar o convênio Sistema Unificado e Descentralizado de Saúde (SUDS), foram medidas impulsionadas por questões nacionais (movimento pela municipalização, descentralização e democratização da saúde) e internas (governo estadual de perfil democrático, com eleição direta) (20).

Na Bahia, assim como em todo o Brasil, a implantação do SUS, nos anos 1990, aconteceu imersa numa conjuntura desfavorável, pois as forças hegemônicas apontavam para reforma restritiva do Estado (redução de funções) e estreitamento das políticas sociais $(21,22)$. Neste contexto, houve a revisão do modelo de regionalização que, em 1991, veio com uma proposta de viabilidade urbana e regional, com a implantação das 31 Dires. Em 2003, o Plano Diretor de Regionalização (PDR) trouxe uma proposta de divisão do estado em sete Macrorregiões de Saúde e 32 Microrregiões. Por sua vez, em 2007, o PDR foi atualizado e reorganizou o estado em nove Macrorregiões e 28 Microrregiões de Saúde (23).

No que diz respeito às Dires, tratam-se de instituições que atravessaram as diferentes fazes do processo político-partidário e das distintas intenções das políticas de saúde na Bahia (24). Ressalta-se que seu desenho original precede ao PDR, por conta disso, seu território de abrangência, nem sempre, coincidia com a Região de Saúde, algumas vezes, mais de uma Dires estava numa mesma região $(17,25)$. As Dires tiveram como finalidade a desconcentração de responsabilidades administrativas da Sesab e a execução de atividades gerenciais junto aos entes municipais, trabalhando com ações de auxílio técnico, monitoramento e avaliação de programas em territórios regionais $(19,26)$.

Porém, o papel da Dires no estado foi sendo obscurecido por diversos fatores e, dentre estes, destacam-se as interferências políticas, a falta de definição do seu papel dentro da rede, o sucateamento das sedes, além da diminuição somada a falta de renovação no quadro de funcionários $(17,19)$. Com isso, algumas Dires passaram a desempenhar um papel burocrático entre os municípios e a Sesab, limitando-se a visitas aos municípios, distribuição de insumos e capacitação de profissionais (25).

Diante deste quadro, em 2014, por meio da Lei n. ${ }^{\circ}$ 13.204, de 11 de dezembro, foram extintas as 31 Dires do estado da Bahia e foram criados nove Núcleos Regionais de Saúde (NRS) que, a partir de então, passaram a ser responsáveis por um maior número de municípios por meio da centralização da gestão regional $(24,27)$.

Diante deste cenário, este artigo analisa o processo de mudança das Diretorias Regionais de Saúde em Núcleos Regionais de Saúde, bem como seus desdobramentos no processo de regionalização na Bahia, Brasil. 


\section{Métodos}

Trata-se de estudo de caso (28), com abordagem qualitativa (29), no campo da saúde pública (30) realizado em quatro Regiões de Saúde, na Bahia, que agregam 73 municípios em seu território.
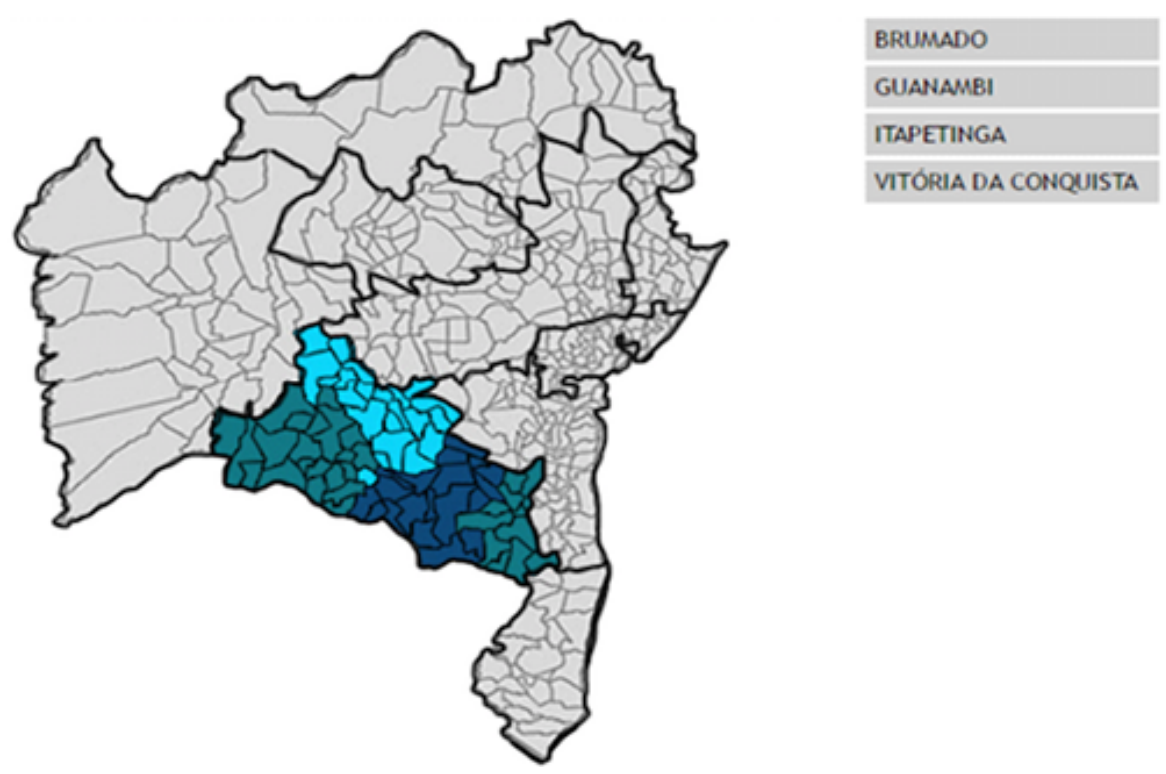

Figura 1. Região de Saúde Sudoeste e suas Regiões de Saúde elaboração própria.

A Bahia é o maior estado da região Nordeste, com uma área de $564.830,859 \mathrm{Km}^{2}$ e uma população estimada em 15,2 milhões habitantes (31), ocupando a $5^{a}$ posição entre os estados brasileiros, em extensão, e a $4^{\mathrm{a}}$, em população. A população do estado distribuise heterogeneamente, num vasto território, com 417 municípios. Destaca-se um desafio à regionalização e à integração da rede de serviços de saúde no estado, visto que a maioria dos entes municipais (aproximadamente 90\%) abriga menos de 50 mil habitantes.

A Região de Saúde é um espaço geográfico contínuo constituído por agrupamentos de municípios limítrofes, com a finalidade de integrar a organização, o planejamento e a execução de ações e serviços de saúde (3).

No caso estudado, elegeu-se a Macrorregião de Saúde Sudoeste que é composta pelas regiões de saúde de Brumado, Guanambi, Itapetinga e Vitória da Conquista (Tabela 1). 
Adriano Maia dos Santos / Fabiana Rodrigues Ferreira dos Santos / Jamille Amorim Carvalho Paiva

Tabela 1. Caracterização das quatro Regiões de Saúde, Bahia, 2016

\begin{tabular}{|c|c|c|c|c|}
\hline Território Sanitário & $\begin{array}{l}\text { Número de } \\
\text { habitantes }\end{array}$ & $\begin{array}{l}\text { Número de } \\
\text { municipios }\end{array}$ & $\begin{array}{l}\text { \% da população } \\
\text { do estado da } \\
\text { Bahia }\end{array}$ & $\begin{array}{l}\text { \% da população } \\
\text { na Macrorregião } \\
\text { Sudoeste }\end{array}$ \\
\hline $\begin{array}{r}\text { Região de Saúde } \\
\text { Brumado }\end{array}$ & 421.748 & 21 & $2,77 \%$ & $23,22 \%$ \\
\hline $\begin{array}{r}\text { Região de Saúde } \\
\text { Guanambi }\end{array}$ & 468.394 & 21 & $3,08 \%$ & $25,79 \%$ \\
\hline $\begin{array}{r}\text { Região de Saúde } \\
\text { Itapetinga }\end{array}$ & 256.134 & 12 & $1,68 \%$ & $14,1 \%$ \\
\hline $\begin{array}{r}\text { Região de Saúde } \\
\text { Vitória da } \\
\text { Conquista }\end{array}$ & 669.703 & 19 & $4,40 \%$ & $36,87 \%$ \\
\hline $\begin{array}{r}\text { Macrorregião } \\
\text { Sudoeste }\end{array}$ & 1.815 .979 & 73 & $11,93 \%$ & $100 \%$ \\
\hline Bahia & 15.203 .934 & 417 & $100 \%$ & - \\
\hline
\end{tabular}

Fuente: Observatório Baiano de Regionalização.

Ressalta-se que, anterior à publicação da Lei n. ${ }^{\circ}$ 13.204, de 11 de dezembro de 2014 (27), existiam, na Macrorregião de Saúde Sudoeste, seis Diretorias Regionais de Saúde (Dires). As Dires estavam localizadas nos seguintes municípios por Região de Saúde: município de Boquira (23 ${ }^{\mathrm{a}}$ Dires - Região de Brumado), município de Caetité (24 ${ }^{\mathrm{a}}$ Dires - Região de Guanambi), município de Brumado (19 Dires - Região de Brumado), município de Guanambi (30 ${ }^{\mathrm{a}}$ Dires Região de Guanambi), município de Itapetinga (14 Dires - Região de Itapetinga) e município de Vitória da Conquista (20a Dires - Região de Vitória da Conquista). 
Diante do cenário descrito, para definição dos sujeitos da pesquisa, elegeram-se onze dirigentes regionais das respectivas Dires (Tabela 2), por meio de indicação de informantes-chave. Para tanto, considerou-se como informantes-chave os sujeitos que acumulavam informações estratégicas acerca da gestão regional na Macrorregião de Saúde Sudoeste. Para a pesquisa, compreendeu-se como dirigentes, os sujeitos que ocupavam lugares estratégicos no aparato da gestão regional (diretores, gerentes ou coordenadores de programas) nas Dires.

Tabela 2. Entrevistados e suas regiões de saúde, Bahia, 2016

\begin{tabular}{|c|c|c|c|c|c|}
\hline Entrevistado & $\begin{array}{c}\text { Dires } \\
\text { correspondente }\end{array}$ & $\begin{array}{c}\text { Instância } \\
\text { atual }\end{array}$ & $\begin{array}{l}\text { Município de } \\
\text { localização }\end{array}$ & $\begin{array}{l}\text { Região de } \\
\text { Saúde }\end{array}$ & \\
\hline G1 & $20^{2}$ Dires & NRS & $\begin{array}{l}\text { Vitória da } \\
\text { Conquista }\end{array}$ & \multirow{3}{*}{$\begin{array}{r}\quad \text { RS } \\
\text { Vitória da } \\
\text { Conquista }\end{array}$} & \multirow{11}{*}{ 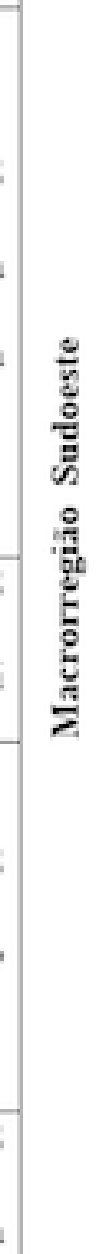 } \\
\hline G2 & $20^{2}$ Dires & NRS & $\begin{array}{l}\text { Vitória da } \\
\text { Conquista }\end{array}$ & & \\
\hline G3 & $20^{a}$ Dires & NRS & $\begin{array}{l}\text { Vitória da } \\
\text { Conquista }\end{array}$ & & \\
\hline G4 & $30^{a}$ Dires & BRS & Guanambi & RS & \\
\hline G5 & $24^{x}$ Dires & BRS & Caetité & Guanambi & \\
\hline G6 & $23^{2}$ Dires & BRS & Boquira & & \\
\hline G7 & $23^{\mathbb{A}}$ Dires & BRS & Boquira & RS & \\
\hline G8 & $19^{2}$ Dires & BRS & Brumado & Brumado & \\
\hline G9 & $19^{2}$ Dires & BRS & Brumado & & \\
\hline G10 & $14^{n}$ Dires & BRS & Itapetinga & RS & \\
\hline G11 & $14^{x}$ Dires & BRS & Itapetinga & Itapetinga & \\
\hline
\end{tabular}

Fuente: elaboração própria.

Nesta perspectiva, os dirigentes eleitos atenderam aos seguintes critérios: 1) gestor/gerente que desenvolvia papel de destaque e com acúmulo de experiência na gestão regional;2) pelo menos 
um gestor/gerente de cada Dires; 3 ) gestores/gerentes com participação periódica na Comissão Intergestores Regional (CIR); 4) gestores/gerentes com, no mínimo, cinco anos de experiência na Dires.

Para definição do número de participantes, levou-se em consideração uma amostragem por redundância de informação, ou seja, por critério de saturação empírica para definição e interrupção da coleta de dados (32). Para produção de dados foram utilizadas entrevistas semiestruturadas (33), realizadas entre maio e junho de 2016.

Utilizou-se roteiros para orientar e guiar os relatos dos entrevistados. O roteiro de entrevistas foi dividido em três blocos temáticos de perguntas. O primeiro bloco abordou sobre a Lei Estadual n. ${ }^{\circ} 13.204$ de 11 de dezembro de 2014 e, portanto, a extinção das 31 Dires e a instituição dos nove Núcleos Regionais de Saúde (NRS) nas sedes das Macrorregiões e das Bases Regional de Saúde (BRS) em substituição as demais sedes de Dires. O segundo bloco tratou sobre a regionalização, debateu-se como foi o processo em cada região de saúde, abordou-se, ainda, sobre a importância da Comissão Intergestores Regional e a atuação dos gestores neste espaço após extinção das Dires. Por fim, o terceiro bloco trouxe questões para discutir o NRS e BRS, no processo de regionalização e no apoio aos municípios em cada região de saúde (Tabela 3). 
Processo de regionalização na Bahia, Brasil: desafios para inovação organizacional

Tabela 3. Síntese do roteiro temático e categorias empíricas

\begin{tabular}{|c|c|}
\hline Temática & Questões propostas \\
\hline 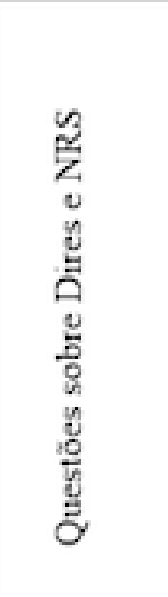 & $\begin{array}{l}\text { - Fale um pouco sobre a mudança das Dires em NRS ou BRS } \\
\text { - Em relação a Lei Estadual que extinguiu as Dires e criou os NRS/BRS (N. } \\
\text { `13.204, de } 11 \text { de dezembro d 2014), como vocês ficaram sabendo? } \\
\text { - Quais as reações logo após a mudança? } \\
\text { - Houve alguma participação, consulta ou outra forma de diálogo na } \\
\text { reorganização das Dires? Como se deu este processo? } \\
\text { - Como tem sido este processo de reorganização das Dires desde então? }\end{array}$ \\
\hline 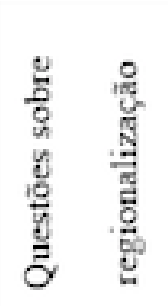 & $\begin{array}{l}\text { - Como tem sido o processo de regionalização da saúde nesta região de saúde? } \\
\text { - Como tem sido o papel/importância da Comissão Intergestores Regional } \\
\text { (CIR) para favorecer a regionalização nesta região de saúde? }\end{array}$ \\
\hline 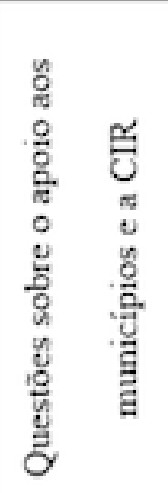 & $\begin{array}{l}\text { - Quais as mudanças no apoio aos municípios em relação ao apoio dado pelas } \\
\text { Dires e atualmente realizado pelo NRS/BRS? } \\
\text { - Em relação a participação da Dires na CIR, como era e como ficou após } \\
\text { mudança para NRS/BRS? } \\
\text { - Qual a importância do NRS no processo de regionalização? }\end{array}$ \\
\hline
\end{tabular}

Fuente: elaboração própria.

Para discussão dos resultados, optou-se pela análise de conteúdo temática (33). As entrevistas foram lidas exaustivamente, trechos com estruturas relevantes e ideias centrais (núcleos de sentido) foram selecionados, agrupados e classificados. 
A pesquisa foi aprovada pelo Comitê de Ética em Pesquisa, da Universidade Federal da Bahia, Instituto Multidisciplinar em Saúde (Parecer 624.168, de 24/04/2014).

\section{Resultados}

Documentos institucionais apontam que, em 2014, iniciou-se um processo de reorganização da administração pública do estado da Bahia que abrangeu modificações na estrutura organizacional de diversas secretarias, entidades e órgãos do poder executivo estadual, materializada por meio da Lei n. ${ }^{\circ} 13.204$, de 11/12/2014 (27). No tocante à saúde, houve a extinção das 31 Diretorias Regionais de Saúde (Dires), que desenvolviam diversas atribuições de competência da Secretaria Estadual de Saúde da Bahia (Sesab) em suas respectivas Regiões de Saúde, e sua substituição por nove Núcleos Regionais de Saúde (NRS) com território adscrito equivalente às Macrorregiões de Saúde definidas pelo Plano Diretor de Regionalização (PDR), de 2007 (34).

Em que pese à manifestação contrária de diversos atores inseridos no contexto do SUS (Conselho Estadual de Saúde, sindicatos, servidores da saúde, professores universitários, políticos etc.) divulgados na mídia e redes sociais, refletindo preocupações com a recentralização do sistema estadual de saúde e redução do papel do estado, a mudança foi justificada nos documentos e pronunciamentos oficiais, dentre outros aspectos, pela necessidade de melhorar a eficiência da gestão pública em um cenário de falta de recursos financeiros ao SUS. Segundo documentos oficiais, a desconcentração da Sesab não era mais necessária cabendo uma reestruturação das diretorias regionais, pois a presença do estado por meio das Dires gerava sobreposição, redundância de funções e ingerência desnecessária nas ações municipais $(35,36)$.

Entretanto, para os entrevistados não houve planejamento prévio para conhecer a real necessidade de mudança e, especialmente, definir quais as Dires precisariam ser extintas na perspectiva de diminuir o gasto com a estrutura administrativa do estado, sendo tomada uma decisão mais burocrática que técnica, de forma abrupta e sem participação dos trabalhadores. Além disso, os dirigentes entrevistados apontaram a ausência de definições da nova modelagem institucional nas regiões e do papel a ser desempenhado pelos servidores das Dires gerou angústia e revolta com o gestor estadual. Em certa medida, os trabalhadores das Dires sentiramse desprestigiados, tratados como pessoas que não tinham utilidade para o serviço público e que, portanto, poderiam ser descartadas de suas atividades e remanejadas sem acordos ou negociações prévias com a Sesab.

Verificou-se nas entrevistas que uma das principais repercussões do processo de mudança nas Dires deu-se na autoestima dos funcionários. Enquanto sujeitos portadores de uma história nas instituições regionais, o rompimento brusco acarretou em desmotivação, insegurança e adoecimento, bem como comprometeu a condução do próprio trabalho cotidiano. Assim, o planejamento institucional da Sesab (ou a falta dele) não vislumbrou a transição para o novo 
Processo de regionalização na Bahia, Brasil: desafios para inovação organizacional

arranjo administrativo, acarretando em período de baixa produtividade, comprometimento dos trabalhos técnicos, a conclusão de projetos e o apoio aos municípios das regiões de saúde. Os relatos a seguir sintetizam tais percepções:

Inicialmente a gente ficou sem saber como fazer, porque a decisão foi tomada, a mudança aconteceu, mas a gente não tinha nenhuma diretriz do nível central. Eles tomaram a decisão, mas não definiram qual era a atribuição do núcleo [NRS], qual era o nosso papel, o que a gente deveria fazer. Então, passamos alguns meses tentando ver o que é que a gente ia fazer, [...] tanto é que 2015 foi um ano praticamente morto, [...] até com as bases [ex-Dires] a gente não sabia como é que ia se direcionar (G1-Vitória da Conquista).

Essa mudança foi bem conflituosa, porque não foi uma coisa discutida com os trabalhadores, foi imposta e isso não foi bem aceito, então deixou muitas sequelas. Eu acredito até em adoecimento, em stress, isso gerou uma insatisfação e a gente viu que não tinha interesse pro governo ter as Dires. Então, a gente se sentiu muito abandonado, pois o governo não via as unidades como importantes, via como um problema e queria se livrar da gente $[\ldots]$ (G8 - Brumado).

Na verdade, dormimos como servidores da Dires e amanhecemos como se a gente não existisse mais. Então, foi um processo que não foi muito discutido nem debatido nos espaços, nas instâncias colegiadas, então pegou a gente de surpresa [...] (G4 - Guanambi).

Como técnico, vejo que faltou um pouco de profissionalismo nessa visão de gestão do SUS no estado, porque poderia trazer à tona a discussão da extinção, da proposta de extinção dessas Dires e nós discutirmos juntos de que maneira isso poderia acontecer. Então, estou consciente de que a possibilidade de extinguir algumas talvez já existisse, então talvez, deveria fazer uma leitura, um diagnóstico de quais não estavam atendendo às expectativas do estado e isso poderia ser identificado através de um levantamento de dados, de indicadores de cada região e aí, a gente poderia juntos, ir construindo isso que iria acontecer lá na frente também, mas não, veio de uma forma abrupta (G10 - Itapetinga).

Outra situação crítica identificada, em 2015, segundo entrevistados, foi a redução do número de servidores lotados nas ex-Dires. Diante das incertezas quanto as funções nas "novas" instâncias regionais, especialmente naquelas que não figuraram como sede de NRS, mas como Bases Regionais de Saúde (BRS), houve um aumento das solicitações de aposentadorias e de pedidos de transferência para outros locais de trabalho. Dessa forma, as ações técnicas de apoio institucional aos municípios, historicamente insuficientes nas Dires, tiveram sua dificuldade acentuada com a diminuição no quadro de funcionários, pois a quantidade de atividades por técnico aumentou, aliada ao desestímulo em realizá-las.

Ainda que comum às seis Dires da Macrorregião Sudoeste, nas quatro regiões de saúde pesquisadas tal evidência foi mais contundente na região de saúde de Vitória da Conquista, uma vez que a $20^{\text {a }}$ Dires tornou-se sede do Núcleo Regional de Saúde (NRS) do Sudoeste, passando a responsabilizar-se oficialmente não mais por 19, mas por 73 municípios que deveriam ser apoiados regularmente. Paralelamente, as demais Dires da Macrorregião Sudoeste (Boquira, Brumado, Caetité, Guanambi e Itapetinga) tornaram-se inicialmente "escritórios", "pontos de apoio" ou ainda "bases operacionais" vinculados ao NRS-Sudoeste, o que significou a perda das suas autonomias gerenciais, tornando-as subordinadas e dependentes da administração do NRS. 
Documento do governo estadual explicita que a mudança visava que o estado assumisse as funções de coordenação, regulação e cooperação técnica e financeira com os municípios (35). Ainda assim, o que transpareceu nos depoimentos dos gestores foi a desorganização do processo de trabalho, diferentes níveis de informação e desentendimento entre os profissionais, sobrecarga de atividades, manutenção ou aprofundamento das precárias estruturas de trabalho e o comprometimento da capacidade das "novas" instâncias em desenvolverem ações na direção do fortalecimento da regionalização, contradizendo a lógica de organização do SUS.

Não obstante, a ausência de diretrizes para nortear a relação entre as "novas" estruturas administrativas explicitou aos servidores que o próprio nível central da Sesab, também, não tinha clareza no direcionamento a ser dado em relação à organização dos trabalhos técnicos e às funções a serem desempenhadas pelo NRS e respectivas Dires da região. De tal modo, foram os servidores das diretorias regionais, que não se tornaram NRS, que se organizaram e propuseram a transformação destas Dires em Bases Regionais de Saúde (BRS), pois a priori muitas delas seriam extintas completamente.

Deste modo, grande parte das ações desenvolvidas na sequência à mudança partiu dos próprios funcionários das unidades regionais que apresentaram suas reivindicações por meio de greves e manifestos, conseguindo junto à Sesab a criação de um grupo de trabalho com o objetivo de discutir conjuntamente o desenho, a estrutura e o funcionamento das instâncias regionais (NRS e BRS), em consonância com o PDR. Assim, mesmo com o posterior enfraquecimento da mobilização dos servidores, o grupo garantiu a permanência das estruturas das Dires (que não se tornaram NRS), denominadas agora de BRS, funcionando com alguma autonomia técnica e administrativa, apesar de terem perdido a autonomia financeira:

\footnotetext{
Deixamos de ser unidade gestora. A gente não trabalha mais com recursos, a gente fica totalmente vinculado e submetido ao núcleo [NRS] de Vitória da Conquista que, também, não tem condições de dar essa assistência na parte administrativa nem técnica, porque, também, tá precisando se estruturar. As ações que a gente desenvolvia antes, agora tá completamente subordinada à programação junto com o núcleo [NRS] (G5 Caetité).
}

Foi uma reação inicial de raiva, a gente ficou com muita raiva, ficou muito frustrado, mas depois veio uma força para a gente se mobilizar. Até que pensei que hoje estou mais parado, mas a gente movimentou muito, fez manifestação, foi na rádio, fez passeata, deu muita cara à tapa. E, aí, como a gente viu que não surtiu muito efeito, assim surtiu de um determinado ponto que ele, a ideia era fechar as Bases, só não fechou as Bases, porque nós nos mobilizamos, mas ia fechar mesmo (G8 - Brumado).

Foi montado um quadro, um grupo interno de técnicos para discussão da regionalização, [...] esse grupo tem uma representação em um grupo maior que tem reuniões periódicas juntamente com o representante da Sesab [...] essas reuniões, se organizam nesse sentido de levar propostas [...] (G2 - Vitória da Conquista).

Os relatos sugerem que o empenho maior da gestão estadual em extinguir a maioria das Dires era diminuir os gastos com cargos comissionados, pois cada Dires tinha um diretor e um 
coordenador administrativo, e centralizar a gestão de recursos financeiros e materiais nos nove Núcleos, em toda a Bahia. Todavia, a extinção dos cargos de diretor nas Dires desestabilizou o direcionamento gerencial dentro das BRS, pois as regionais que se transformaram em BRS ficaram sem uma referência administrativa local para coordenar as atividades internas e, assim, tiveram que buscar, dentre os servidores, alguém que, "por boa vontade", pudesse assumir de forma temporária a função ocupada pelo diretor/administrador da Dires. Tal situação ocorreu uma vez que o governo estadual definira apenas os cargos de direção para os nove NRS em todo o estado, deixando os trabalhadores das demais Dires sentindo-se órfãos no aspecto direcional.

Sobressaiu, além disso, o atraso no fluxo dos projetos, visto que antes os documentos eram assinados pelo diretor na própria Dires (atuais BRS). Com a centralização dos cargos deliberativos nos NRS, no caso da Macrorregião Sudoeste, os documentos passaram a ser encaminhados à Vitória da Conquista para assinatura da coordenadora (no NRS) e retornavam à sede das demais BRS, aumentando a burocracia e diminuindo a agilidade na tomada de decisões.

Noutro sentido, destaca-se que um dos depoimentos revelou nuances graves na conduta de trabalho de alguns servidores das Dires, o que teria potencializado a tomada de decisão do governo estadual pela restruturação administrativa das instâncias regionais. Entre os problemas elencados, a declaração do entrevistado destacou o não cumprimento das funções e da carga horária de trabalho atribuídas, o descompromisso com a frequência ao trabalho, a grande quantidade de atestados e, em alguns casos, o exercício paralelo de funções em outros serviços. Este somatório de problemas é emblemático e revela as contradições do funcionalismo público, bem como explicita o jogo de interesses de alguns agentes públicos em manter privilégios em detrimento das instituições e da população. $\mathrm{O}$ fragmento adiante traz tal paradoxo:

Tínhamos uma gama de servidores que já estava muito à vontade, porque, queira ou não, [...], muitos querem ir trabalhar sem alguém que lhe obrigue a cumprir sua carga horária. Diretor, por ser um cargo político, dificilmente procura entrave com servidor, e aí a gente já identificava que algumas coisas tinham que mudar no estado. Muita gente com 40 [horas] que não queria trabalhar nos dois turnos, muita gente que ia trabalhar no dia que quisesse, muita gente que tinha um programa X para dar conta e não dava mais. Então, tava uma situação que se precisava tomar uma medida radical, [...] alguma mudança que venha otimizar a função das Dires. Aí, eu diria que até a extinção de algumas não tinha problema não, porque nós tínhamos algumas que o governo já tinha identificado que não estavam mais rendendo, para os olhos da Sesab, como deveriam render. [...] porque pagar um médico, pagar uma enfermeira, pagar um técnico de enfermagem que durante $\mathrm{X}$ período dava não sei quantos atestados, mas que tem outro vínculo não sei onde, aí não dá, pagar um servidor que pediu uma licença médica, mas ta trabalhando em outro estado, até em outra cidade do estado, dando plantão! Então, havia um quantitativo de motivos que, acredito, levou o governo a tomar essa decisão. Eu sou contra a extinção generalizada que ele fez e a forma como fez, mas acho que alguma coisa deveria ser feita, porque realmente estava um pouco solto há um bom tempo (G10 - Itapetinga).

Para alguns entrevistados, ainda que tais desvios de conduta não fossem generalizados, havia mesmo a necessidade de mudança; porém a forma arbitrária como foi realizada gerou revolta. Inicialmente, este sentimento deu força e motivação para lutar pela permanência das Dires. Entretanto, a resistência de negociação do governo e a "racionalidade gerencial" do secretário estadual de saúde levaram o movimento a perder força, gerando nos servidores mais 
comprometidos e que tinham uma história na construção de políticas regionais, uma sensação de retrocesso e ingratidão institucional. Salienta-se que, apesar de todo o movimento em defesa das Dires e das discussões feitas no âmbito do grupo de trabalho, oficialmente existem apenas nove NRS no estado, ou seja, as BRS ainda não foram regulamentadas, mesmo exercendo, na prática, função técnica e administrativa no seu território. Os trechos dos gestores entrevistados reforçam tais considerações:

Legalmente, não somos nada, somos uma extensão do núcleo [NRS], estamos todos lotados no núcleo, porém executando a parte técnica [nas outras regionais]. A gente não tem autonomia nenhuma, muito mal autonomia técnica pra devolver o papel enquanto técnico, mas só. Então, tudo que se avançou no processo de descentralização, regionalização, de construção, de processo de trabalho, retrocedeu há trinta anos praticamente, e isso que a gente tá vivendo agora foi o que a gente viveu no início do processo de municipalização, do processo de construção do SUS quando Conquista era a macro, a sede das Dires (G7 - Boquira).

A postura do secretário de estado também foi muito assim... ele é uma pessoa que não tem a vivência, uma visão em Saúde Coletiva, ele é da área hospitalar, ele trabalhava em um hospital [...]. Outra coisa importante, o estado investiu na nossa qualificação, promoveu muitos cursos de qualificação. Eu mesma fiz dois cursos de especialização via estado e fiz o mestrado profissional, então, assim, o estado investiu em mim e ao mesmo tempo que investe, ele desvaloriza. Então, você deixa de acreditar, isso é muito ruim, você tem que acreditar em alguma coisa para estar motivada, tem que acreditar no que faz. É como se puxasse seu tapete e você fica sem chão (G5 - Caetité).

Para os entrevistados, num primeiro momento, a mudança administrativa não trouxe vantagem para o processo de regionalização. De acordo com os gestores, o primeiro ano sem as Dires, e com apenas um Núcleo de saúde responsável por 73 municípios para apoiar, comprometeu muito a qualidade das ações. Por outro lado, como possível ganho, os gestores apontaram a economia de escala sob o ponto de vista de compra dos insumos de maneira mais centralizada entre os NRS; uma vez que houve a reconfiguração das 31 Dires em nove NRS.

Além disso, a maior integração entre os funcionários lotados no NRS-Sudoeste também foi um ponto positivo registrado, que se refletiu em maior frequência de encontros entre as equipes técnicas das regionais das quatro diferentes regiões de saúde. Isto possibilitou que o planejamento das ações das regiões fosse em conjunto, a construção e a execução dos projetos tivessem a participação de representantes de toda a Macrorregião de Saúde Sudoeste e permitiu, ainda, que as BRS com maior organização/quantidade de técnicos auxiliassem as BRS com maior dificuldade. Toda esta conexão minimizou os impactos negativos nas regiões de saúde, além do apoio mútuo ter aumentado.

Enxergo uma mudança positiva: acho que a economicidade sob o ponto de vista de aquisição de material é válida, acho que ao invés de ter fornecimento para 31 unidades de gestão, sob o ponto de vista de compra, e você ter só nove, acho positivo. Acho que essa mudança da Dires seria válida se tivesse sido dentro de um contexto de fortalecimento da região e não tirando todos os direitos dos servidores, pois isso impactou bastante [...] (G2 - Vitoria da Conquista). 
Um dos ganhos é que a gente tá integrando mais. A gente tem mais contato com o pessoal de Itapetinga, de Boquira, de Conquista, a gente até se ajuda mais, acho que esse é um dos ganhos. Acho que o restante, são perdas [...] (G8 - Brumado).

Além das questões organizativas, uma determinação do governo que também impactou na redução das equipes de trabalho das Dires foi a perda do adicional de insalubridade concedido aos servidores. Tal perda financeira motivou muitos funcionários a solicitarem transferência para locais de trabalho onde não haveria perda, a exemplo de unidade hospitalares e outros serviços assistenciais, uma vez que o adicional de insalubridade variava de $20 \%$ a $40 \%$ do vencimento básico dos servidores.

\section{Discussão}

Entre as contradições na reforma administrativa, destaca-se a perda do protagonismo de referência institucional das diretorias regionais aos municípios, sobretudo àqueles de menor porte populacional e com dificuldades em ter um corpo técnico suficiente. No entanto, o apoio regional é uma prerrogativa para fortalecimento da regionalização, na perspectiva de promover a articulação técnica na política intermunicipal $(26,37)$ para viabilizar a integração da rede de atenção $(19,38)$.

Não obstante, com a extinção das Dires, o NRS concentrou os recursos financeiros de todas as seis Dires da Macrorregião Sudoeste. Neste sentido, é importante frisar que as Dires já enfrentavam dificuldades na operacionalização de suas atividades nas regiões de saúde, por questões financeiras, insuficiência de servidores e sucateamento das estruturas de trabalho $(17,19)$. Assim, a concentração administrativa e financeira em NRS não logrou mudanças na qualidade das condições de trabalho, nem tão pouco no aporte de recursos para fortalecimento do apoio regional. Não por acaso, houve "necessidade de se manter as estruturas físicas das antigas Dires em funcionamento, como bases operacionais vinculadas aos NRS na macrorregião de saúde de abrangência" (24).

Dentre as desvantagens da mudança administrativa, problemas gerenciais e de infraestrutura vivenciados pelo NRS ocasionaram a diminuição das viagens para visitas técnicas e apoio institucional aos municípios das regiões de saúde. Tal questão é um paradoxo à regionalização, pois num estado com 417 municípios, o papel do estado torna-se imperativo para apaziguar interesses divergentes e necessidade comuns entre entes com acentuadas assimetrias de poder técnico e financeiro (11).

Mesmo com a mudança das Dires para NRS e manutenção de outras apenas como bases regionais de saúde (BRS), percebeu-se que na Macrorregião Sudoeste houve uma rearticulação dos processos de trabalho que minimizou os atritos e estabeleceu uma rotina técnica semelhante ao funcionamento anterior. Um motivo que facilitou a boa relação entre as BRS e o NRS foi creditado à capacidade de articulação e negociação da coordenadora do NRS-Sudoeste, que teve uma visão estratégica e de apoio ao trabalho das BRS, reconhecendo a necessidade de parceria e transparência institucional. Tal evidência sinaliza a importância de "um trabalho 'técnico- 
político' orientado pelos princípios e diretrizes do SUS" (39), especialmente, num estado cujas práticas clientelistas locais atravessam os interesses públicos coletivos $(17,40,41)$.

Outrossim, ainda que a extinção das Dires tenha ocorrido de forma traumática e que se tenha passado por um difícil processo de adaptação entre os servidores, constatou-se que a relação entre NRS e BRS mostrava-se produtiva, com perspectiva de integração e participação dos diferentes sujeitos envolvidos na construção das ações em saúde e na luta por uma melhor organização do SUS no estado da Bahia. A definição do processo de trabalho das BRS e sua articulação cordial com a direção do NRS, dentro da gestão compartilhada nas regiões de saúde, permitiram a atenuação dos conflitos. Ademais, a regionalização no território baiano é intrinsicamente dependente da desconcentração das ações da Sesab, diante da dimensão territorial e das complexas relações intermunicipais $(19,24)$.

Outro aspecto relevante foi o impacto da reforma administrativa nas Comissões Intergestores Regionais (CIR), instâncias de pactuação entre gestores do SUS no estado da Bahia sobre as competências definidas dentro do seu território (42). A Macrorregião de Saúde Sudoeste é composta por quatro regiões de saúde, cada uma com a sua respectiva CIR. Antes da reforma, em cada CIR havia um assento destinado ao diretor da Dires e outro destinado a um técnico designado por ele. Neste aspecto, mesmo com a extinção das Dires, todas as CIR permaneceram funcionando normalmente, sendo que a coordenação do NRS passou a participar das reuniões nas quatro diferentes CIR. O ponto crítico é a dificuldade do NRS participar de todas as reuniões da CIR e, ainda, alinhar interesses entre 73 gestores municipais.

Além disso, as CIR já eram devedoras de um trabalho mais organicamente envolvido com os problemas regionais $(10,12)$, ou seja, a perda de poder das diretorias regionais, também, sinalizou uma inversão na lógica de fortalecimento de uma governança regional (19).

Segundo a Resolução CIB n. ${ }^{\circ}$ 088/2013 (43), a CIR era composta por três representantes do estado, sendo dois do nível regional e um do nível central, além dos secretários municipais de saúde de cada região. Nas situações em que a Região de Saúde abrangia duas Dires, a Sesab passava a ter quatro representantes na CIR: os dois diretores das Dires e os dois membros efetivos (um representante do nível central e um técnico da Dires situada na cidade sede da Região de Saúde). Na perspectiva do fluxo de funcionamento, as CIR continuaram realizando reuniões mensais dentro da normalidade, dando seguimento às discussões e às aprovações das sessões regulares. Todavia, com a reforma administrativa, nas Regiões de Saúde anteriormente compostas por duas Dires (exemplo: RS Guanambi, composta pelas Dires de Guanambi e Caetité; RS Brumado, composta pelas Dires de Brumado e Boquira), houve a perda de um membro efetivo dentro da CIR, que era uma voz ativa dentro da comissão.

É importante destacar, também, que a direção da Dires sempre foi um cargo de confiança da Sesab que, por sua vez, era permeável às forças políticas regionais, sendo, portanto, uma 
instância com relevante peso político-partidário nas regiões de saúde $(21,24,40)$. Com a extinção das Dires, a representação dos dois diretores passou a ser feita pelo coordenador do NRS, ficando a BRS, que não é sede de região de saúde, sem representantes na CIR.

Por fim, aponta-se para uma reestruturação das diretorias regionais desarticulada à lógica da regionalização. Na perspectiva da reforma administrativa do estado, a solução encontrada para diminuição do gasto com pessoal e com as estruturas não contemplou as necessidades regionais, nem tampouco parece ter se atentando para as pessoas que desenvolviam as atividades nestas instâncias, acarretando em conflitos e insatisfações que poderiam ter sido minimizadas. Por sua vez, as evidências trazem elementos muito mais relacionados à preocupação com a perda de certo "modus operandi” de cada Dires que, essencialmente, com os impactos na regionalização.

Entre outras coisas, as Dires desenvolviam ou poderiam desenvolver um vigoroso apoio institucional aos municípios nas regiões de saúde (17, 26, 38). Assim sendo, os NRS precisarão responder a uma demanda de fortalecimento das redes regionais de saúde $(19,25)$ que, por sua vez, requererá do ente estadual criar condições técnicas e institucionais, sobretudo, na perspectiva de uma governança regional sob domínio do interesse público.

\section{Conclusões}

A integração assistencial e a coordenação do cuidado entre os municípios, nas regiões de saúde, para constituição de redes de atenção à saúde regionalizadas deveriam ser os princípios técnicos preponderantes na tomada de decisão, posto que a Bahia é um estado com 417 municípios que necessitam de articulação entre si. Neste aspecto, a Sesab, por meio das Dires, poderia orquestrar tais estratégias organizacionais, sendo que a mudança nas estruturas regionais deveria, portanto, privilegiar tal desafio político-institucional.

Desta forma, considera-se que os problemas estruturais, de financiamento e de número de servidores nas "antigas" Dires comprometiam o apoio institucional nas regiões de saúde. Todavia, o mais sensato seria o planejamento junto às CIR para redefinição da modelagem regional que respondesse mais adequadamente aos diferentes territórios e, portanto, as unidade regionais da Sesab poderiam ser reconfiguradas para ampliação da presença direta do estado nos territórios sanitários.

Ademais, a mudança das Dires em NRS e BRS manteve as antigas estruturas com outros nomes, conservou certos modos de trabalho e gerou o esvaziamento do apoio institucional nas regionais. Neste sentido, contraditoriamente, não logrou o fortalecimento das práticas institucionais para viabilizar a integração regional e a efetivação da integralidade do direito à saúde.

Não obstante, negligencia-se e reduze-se o espaço para reflexão e decisão compartilhada com os sujeitos envolvidos na reforma administrativa, ou seja, uma clássica centralização normativa e descentralização executiva. 
Conclui-se que o processo de mudança das Dires em NRS foi uma decisão mais burocrática que técnica, abrupta e sem participação dos trabalhadores, bem como, resultou em perda do protagonismo da diretoria regional como apoiadora institucional aos municípios nas regiões de saúde.

\section{Referências}

1. Brasil. Ministério da Saúde. Norma Operacional da Assistência à Saúde - NOAS-SUS 01/01 (Portaria MS/ GM n. ${ }^{\circ}$ 95, de 26 de janeiro de 2001, e regulamentação complementar). Série A. Normas e Manuais Técnicos. Brasília: Ministério da Saúde; 2001.

2. Brasil. Ministério da Saúde. Portaria 399, 22 fev. 2006. Divulga o Pacto pela Saúde 2006 - Consolidação do SUS e aprova as Diretrizes Operacionais do Referido Pacto. Brasília: Ministério da Saúde; 2006.

3. Brasil. Ministério da Saúde. Regulamentação da Lei 8.080 para fortalecimento do SUS: decreto 7508, de 2011. Rev. Saúde Públ. 2011;45(6):1206-1207.

4. Kuschinir R, Chorny AH. Redes de atenção à saúde: contextualizando o debate. Cien Saúde Colet. 2010;15(5):2307-2316.

5. Viana ALA, Bousquat A, Melo GA, Negri Filho A, Medina MG. Regionalização e Redes de Saúde. Cien Saúde Colet. 2018;23(6):1791-1798.

6. Silva CR. Dificuldade de acesso a serviços de média complexidade em municípios de pequeno porte: um estudo de caso. Cien Saúde Colet. 2017;22(4):1109-1120.

7. Duarte CMR, Pedroso MM, Bellido JG, Moreira RS, Viacava F. Regionalização e desenvolvimento humano: uma proposta de tipologia de regiões de saúde no Brasil. Cad. Saúde Pública. 2015;31(6):1163-1174.

8. Lima LD, Queiroz LFN, Machado CV, Viana ALA. Descentralização e regionalização: dinâmica e condicionantes da implantação do Pacto pela Saúde no Brasil. Cien Saúde Colet. 2012;17(1):1903-1914.

9. Carvalho ALB. Regionalização no SUS: processo de implementação, Desafios e perspectivas na visão crítica de gestores do sistema. Cien Saúde Colet. 2017;22(4):1155-1164.

10. Santos AM, Giovanella L. Gestão do cuidado integral: estudo de caso em região de saúde da Bahia, Brasil. Cad. Saúde Pública. 2016;32(3):e00172214.

11. Almeida PF, Santos AM, Santos VP, Silveira-Filho RM. Integração assistencial em região de saúde: paradoxo entre necessidades regionais e interesses locais. Saúde Soc. 2016;25(2):320-335.

12. Silveira-Filho RM, Santos AM, Carvalho JÁ, Almeida PF. Ações da Comissão Intergestores Regional para gestão compartilhada de serviços especializados no Sistema Único de Saúde. Physis. 2016;26(3):853-878. 
13. Viana ALD, Lima LD. Regionalização e relações federativas na política de saúde do Brasil. Rio de Janeiro: Contra Capa; 2011.

14. Dourado DA, Elias PEM. Regionalização e dinâmica política do federalismo sanitário brasileiro. Rev. Saúde Públ. 2011;45(1):202-211.

15. Lima LD, Machado CV, Baptista TWF, Pereira AMM. O pacto federativo brasileiro e o papel do gestor estadual no SUS. Em: Ugá MAD, Sá MC, Martins M, Braga-Neto FC, editores. A gestão do SUS no âmbito estadual: o caso do Rio de Janeiro. Rio de Janeiro: Fiocruz; 2010. p. 27-58.

16. Santos L, Campos GWS. SUS Brasil: a região de saúde como caminho. Saúde Soc. 2015;24(2):438-446.

17. Santos AM. Redes regionalizadas de atenção à saúde: desafios à integração e à coordenação do cuidado. Salvador: Edufba; 2018.

18. Spedo SM, Pinto NRS, Tanaka OY. A regionalização intramunicipal do Sistema Único de Saúde (SUS): um estudo de caso do município de São Paulo-SP, Brasil. Saúde Soc. 2010;19(3):533-546.

19. Biscarde DGS. Gestão regional do SUS nas regiões metropolitanas de Salvador e de Fortaleza: instâncias, processos de pactuação e relações de poder [tese de doutorado]. [Salvador (BA)]: Instituto de Saúde Coletiva, Universidade Federal da Bahia; 2016.

20. Teixeira CF, Paim JS, Araújo EC, Formigli VLA, Costa HG. O contexto político-administrativo da implantação de Distritos Sanitários no estado da Bahia, Brasil. Cad. Saúde Pública. 1993;9(1):79-84.

21. Coelho TCB, Paim JS. Processos decisórios e prática de gestão: dirigindo a Secretaria de Saúde do Estado da Bahia, Brasil. Cad. Saúde Pública. 2005;21(5):1373-1382.

22. Soares LTR. Os custos sociais do ajuste neoliberal na América Latina. 2. ${ }^{a}$ ed. São Paulo: Cortez: 2002.

23. Secretaria da Saúde do Estado da Bahia. Plano Estadual de Saúde 2016 a 2019. Rev. Baiana Saúde Púb. 2016;40(Suppl 3):1-124.

24. Molesini JAO, Mattos HNR. Regionalização do Sistema Único de Saúde na Bahia. Bahia Anál. Dados. 2016;26(2):287-307.

25. Santos AM, Assis MMA. Processo de regionalização da saúde na Bahia: aspectos políticos-institucionais e modelagem dos territórios sanitários. G\&DR. 2017;13(2):400-422.

26. Pinheiro MEC, Jesus LMM. Apoio institucional como diretriz de gestão da $7^{\text {a }}$ Diretoria Regional de Saúde, Bahia, Brasil. Interface - Comunic., Saude, Educ. 2014;18(Suppl 1):1135-1143.

27. Secretaria da Saúde do Estado da Bahia. Casa Civil da Bahia. Lei 13.204. Modifica a estrutura organizacional da Administração Pública do Poder Executivo Estadual e dá outras providências [Internet]. Salvador: Sesab; 2014 [revisão 2016 dez. 4]. Disponível em: http://www.legislabahia.ba .gov.br/verdoc.php

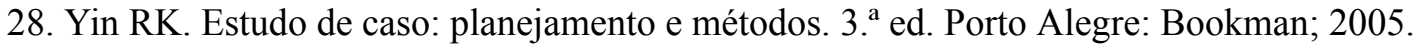

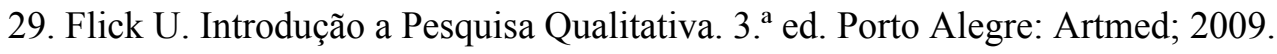

30. Navarro MIJ. La investigación en salud pública: una reflexión epistemológica desde las ciencias de la complejidad. Rev. Gerenc. Polit. Salud. 2009;8(16):32-56. 
31. Instituto Brasileiro de Geografia e Estatística. IBGE Estados [Internet]. 2016 [revisão 2016 dez. 4]. Disponível em: http://www.ibge.gov.br/estadosat/perfil.php

32. Fontanella BJB, Luchesi BM, Saidel MGB, Ricas J, Turato ER, Melo DG. Amostragem em pesquisas qualitativas: proposta de procedimentos para constatar saturação teórica. Cad. Saúde Pública. 2011;27(2):389-394.

33. Minayo MCS. O desafio do conhecimento: pesquisa qualitativa em saúde. 14. ${ }^{\mathrm{a}}$ ed. São Paulo: Hucitec; 2014.

34. Secretaria da Saúde do Estado da Bahia. Plano Diretor de Regionalização do Estado da Bahia. Salvador: Sesab; 2008.

35. Secretaria da Saúde do Estado da Bahia. Diretorias Regionais de Saúde (Dires): 5 Pontos para Compreensão [Internet]. Salvador: Sesab; 2015 [revisão 2016 dez. 4]. Disponível em: http://www.s aude.ba.gov.br/novoportal/index.php?com

36. Secretaria da Saúde do Estado da Bahia. Comunicado da Sesab aos servidores [Internet]. Salvador: Sesab; 2015 [revisão 2016 dez. 4]. Disponível em: http://www.saude.ba.gov.br/novoportal/index.ph p?option $=\mathrm{com}_{-}$

37. Paschoalotto MAC, Passador JL, Oliveira LR, Lopes JEF, Dantas MK, Passador CS. A regionalização do SUS: proposta de avaliação de desempenho dos Departamentos Regionais de Saúde do estado de São Paulo. Saude Soc. 2018;27(1):80-93.

38. Almeida PF, Santos AM. Diálogos em busca de coordenação do cuidado: linha de chegada ou novo itinerário? Em: Almeida PF, Santos AM, Souza MKB, editores. Atenção Primária à Saúde na coordenação do cuidado em regiões de saúde. Salvador: Edufba; 2015. p. 277-303.

39. Andrade MC, Castanheira ERL. Cooperação e apoio técnico entre estado e municípios: a experiência do programa articuladores da atenção básica em São Paulo. Saúde Soc. 2011;20(4):980-990.

40. Guimarães MCL. Processo decisório e conflitos de interesse na implantação da descentralização da saúde: um estudo das instâncias colegiadas na Bahia. Cad. CRH. 2003;16(39):105-132.

41. Bispo-Júnior JP. Participação em Saúde: avanços e entraves na democratização do poder político. Salvador: Edufba; 2015.

42. Secretaria da Saúde do Estado da Bahia. Serviço Público Estadual. Resolução CIB n. ${ }^{\circ}$ 011/2015, 11/02/2015. Aprova Regimento Interno da CIB e das CIR do Estado da Bahia. Salvador: Sesab; 2015.

43. Secretaria da Saúde do Estado da Bahia. Resolução CIB n. ${ }^{\circ}$ 088/2013. Aprova o regimento interno da CIB e das CIR do Estado da Bahia. Diário Oficial. Salvador: Sesab; 2013.

\section{Notas}

* Artigo de pesquisa. Entidade financiadora: Fundação de Amparo à Pesquisa do Estado da Bahia (FAPESB) - Edital FAPESB n. ${ }^{\circ}$ 08/2015. Termo de outorga $\mathrm{n}^{\mathrm{o}} \mathrm{JCB} 0003 / 2016$. 